\title{
Elstera litoralis gen. nov., sp. nov., isolated from stone biofilms of Lake Constance, Germany
}

\author{
Monali Rahalkar,† Rahul A. Bahulikar,† Jörg S. Deutzmann, Peter G. Kroth \\ and Bernhard Schink
}

Correspondence

Bernhard Schink

bernhard.schink@uni-konstanz.de
Fachbereich Biologie, University of Konstanz, 78457 Konstanz, Germany

An alphaproteobacterium, strain Dia- $1^{\top}$, was isolated from algae-dominated biofilms on stones from the littoral zone of Lake Constance, Germany. This bacterium was isolated after initial enrichment in spent medium obtained after growth of a diatom culture. Numerous sugars and some organic acids and alcohols served as growth substrates. The bacterium grew slowly, was strictly aerobic but microaerophilic, and did not grow in cultures shaken under air. 16S rRNA gene sequence analysis indicated that strain $\mathrm{Dia}-1^{\top}$ was distantly related to representatives of the genera Azospirillum (90-91\% sequence similarity), Skermanella (88-89\%), Rhodocista (87$88 \%$ ) and Dongia (88-89\% sequence similarity). Based on this sequence comparison, on phenotypic characterization including substrate utilization patterns, and comparison of cellular fatty acids, quinones, polar lipids and polyamines, this isolate was found to be substantially different from the genera mentioned above. On the basis of these results, a novel genus and species is proposed for this strain. The name Elstera litoralis gen. nov., sp. nov. is suggested, with strain $\mathrm{Dia}-1^{\top}\left(=\mathrm{DSM} 19532^{\top}=\right.$ LMG $\left.24234^{\top}\right)$ as the type strain of the type species.
Lake Constance is a mesotrophic, phosphate-limited hardwater pre-alpine lake (Schmieder et al., 2005), and the second largest freshwater lake in Europe. The infra-littoral zone consists of stones that are covered with biofilms. The shallow upper-littoral zone of lentic periphyton communities is often dominated by diatoms and green algae (Stevenson et al., 1996). Diatoms and bacteria are the pioneers in developing photic biofilms (Rao et al., 1997), and the extracellular polysaccharides (EPS) produced by the diatoms are an important source of organic carbon for heterotrophic bacteria in such biofilms (Bruckner et al., 2008). In turn, the diatom cells also profit from the presence of heterotrophic bacteria in the culture (Bruckner et al., 2008). In an attempt to analyse metabolic interactions between diatoms and accompanying bacteria in more depth, we aimed to cultivate biofilm-associated bacteria living in close cooperation with diatoms. Strain Dia-1 was isolated from a stone biofilm as a numerically dominant bacterium after initial growth with isolated diatom EPS.

Diatoms were isolated from biofilms growing on stones at $20-40 \mathrm{~cm}$ water depth in the littoral zone $\left(47^{\circ} 41^{\prime} \mathrm{N}\right.$; $\left.9^{\circ} 11^{\prime} \mathrm{E}\right)$ of Lake Constance, Germany. Unialgal, nonaxenic and axenic diatom cultures were established by repeated screening and/or antibiotic treatment, and were

†These authors contributed equally to this work.

Abbreviation: DM, Diatom Mineral Medium.

The GenBank/EMBL/DDBJ accession number for the 16S rRNA gene sequence of strain Dia-1 is EU678309. maintained in Diatom Mineral Medium (DM; Watanabe, 2005) at $16{ }^{\circ} \mathrm{C}$ in a $16: 8 \mathrm{~h}$ light-dark cycle using coolwhite fluorescent tubes $\left(50 \mu \mathrm{mol}\right.$ photons $\left.\mathrm{m}^{-2} \mathrm{~s}^{-1}\right)$, in stationary culture without shaking or aeration.

Unialgal axenic diatoms were isolated as previously described (Bahulikar \& Kroth, 2008). Four of these axenic diatom strains, Cymbella microcephala (isolates B-04, I-04 and D-23) and Cymbella minuta (isolate I-51) were grown in 11 flasks containing $600 \mathrm{ml} \mathrm{DM}$ and were allowed to grow to stationary phase. Possible bacterial contamination was checked microscopically following staining with SYBR Green (Invitrogen Inc.) according to the manufacturer's instructions. After confirming the diatom cultures were axenic, cells were removed by centrifugation at 10000 r.p.m. for $10 \mathrm{~min}$ and the spent medium was used in experiments for enrichment of heterotrophic bacteria. The medium was checked microscopically for remnants of diatom cells or any contaminating bacteria. Soluble EPS were quantified by a carbohydrate assay (DuBois et al., 1956) before and after bacterial growth.

For isolation of biofilm-associated bacteria, stones from the littoral zone (20-30 cm water depth) of Lake Constance, Germany were collected on 19 August 2006. Epilithic biofilms were scraped off and pooled in a Falcon tube. Approximately $2.5 \mathrm{ml}$ biofilm material was diluted with $\mathrm{DM}$ to $25 \mathrm{ml}$ and vortexed vigorously for 2-3 min until most of the particles were well-suspended. The suspension was further mixed by pipetting and was serially diluted in $1: 10$ steps up to $10^{-8}$, with vortexing for $1-2 \mathrm{~min}$ at each 
step to disperse the bacteria evenly. A $5 \mathrm{ml}$ aliquot of each diluted suspension was used to inoculate $45 \mathrm{ml}$ spent medium from diatom cultures containing soluble EPS in $100 \mathrm{ml}$ flasks. Flasks were incubated at $25^{\circ} \mathrm{C}$ in the dark for 15 days without shaking, with mixing of contents after 3-4 days. The final optical density of the cultures was recorded after 2 weeks, and samples were taken on days 8 and 15 for quantification of soluble EPS as described above. Non-inoculated flasks served as controls and were incubated in the same manner.

The two highest dilution cultures showing positive growth were used for isolation of the numerically dominant bacteria utilizing the diatom-produced EPS in the spent media. Bacteria from lower dilutions were also plated to check for the overall diversity. Approximately $20 \mu \mathrm{l}$ samples of these dilutions were streaked on two different agar plates $[1: 2$ - or $1: 10$-diluted nutrient broth solidified with $1.5 \%(\mathrm{w} / \mathrm{v})$ agar (Difco) and containing $10 \mathrm{mM}$ glucose] and incubated at $23{ }^{\circ} \mathrm{C}$ until colonies were visible. Bacteria were examined with a phase-contrast microscope (Axiophot; Zeiss) and restreaked until homogeneous colonies and microscopically pure cultures were obtained. Cells were observed and photographed with a phase-contrast microscope (Axiophot; Zeiss) and a cooled charge-couple device camera (Magnafire; INTAS).

Strain Dia- $1^{\mathrm{T}}$ was isolated from the final plated dilution of the biofilm sample where EPS was used as the carbon source. Growth of strain Dia- ${ }^{\mathrm{T}}$ in VM-ethanol medium (Reinhold-Hurek \& Hurek, 2000) was investigated.

For growth tests on API 20NE and Biolog PM1 microplates, fresh colonies grown in 1:10-diluted nutrient broth supplemented with $10 \mathrm{mM}$ glucose were used. Results were recorded after incubation for $4-6$ days at $20-22{ }^{\circ} \mathrm{C}$.

Analysis of total fatty acids, respiratory quinones and polar lipids were carried out by the Identification Service of the DSMZ and Dr B. J. Tindall, DSMZ, Braunschweig, Germany. Cells were grown in $1: 10$ diluted nutrient broth with $10 \mathrm{mM}$ glucose at $22{ }^{\circ} \mathrm{C}$ into late exponential phase, pelleted and freeze-dried before lipid analysis. Fatty acid methyl esters were extracted from the cells following saponification and methylation, and were subjected to gas chromatography. The gas-chromatographic elution profile of the fatty acid methyl esters was compared with the fatty acid patterns in the database of the Microbial Identification System (MIS, MIDI), and qualitative and quantitative composition of the profile were given. Polyamines were extracted and analysed by Dr H.-J. Busse, Institut für Bakteriologie, Mykologie und Hygiene, Veterinärmedizinische Universität, Vienna, Austria (Busse \& Auling, 1988; Stolz et al., 2007).

Fixation of molecular nitrogen was investigated in mineral medium devoid of ammonium or nitrate. Nitrogenase activity was assayed by the acetylene reduction assay (Stewart et al., 1967). To check for the presence of nif genes, genomic DNA of strain Dia-1 was extracted using a modified
CTAB method (Murray \& Thompson, 1980). Cells were grown, pelleted, suspended in CTAB extraction buffer and heated at $65{ }^{\circ} \mathrm{C}$ for $30 \mathrm{~min}$ followed by Chl:IAA extraction and ethanol precipitation. Partial amplification of nifH gene was carried out using a nested approach described by Zani et al. (2000).

DNA was extracted, used for amplification of the $16 \mathrm{~S}$ rRNA gene and sequenced as previously described (Rahalkar et al., 2007). The DNA G + C content was analysed by the Identification Service, DSMZ, Braunschweig, Germany, following the method of Mesbah et al. (1989).

16S rRNA gene sequences of type strains related to strain Dia$1^{\mathrm{T}}$ were downloaded from the NCBI database and aligned using the SINA aligner (http://www.arb-silva.de/aligner/). Phylogenetic analysis of the 16S rRNA gene sequences of strain Dia-1 and related strains was performed with MEGA software version 5 (Tamura et al., 2011). Gluconacetobacter diazotrophicus PAI $5^{\mathrm{T}}$ was used as an outgroup.

Dilution cultures of homogenized biofilm material were incubated in medium with EPS of diatoms as sole source of carbon and energy for up to 15 days. Growth was observed up to the final dilution in the form of biofilms at the bottom of the flasks. After streaking on 1:10-diluted nutrient broth agar plates containing $10 \mathrm{mM}$ glucose, various colonies were observed, and one of the most common colony types was used for isolating strain Dia- $1^{\mathrm{T}}$.

Strain Dia- $1^{\mathrm{T}}$ was isolated from agar plates originally inoculated with the $10^{-8}$ dilution by repeated streaking on the same agar medium. It also grew well in $1: 2$-diluted nutrient broth supplemented with $10 \mathrm{mM}$ glucose, and in VM medium with ethanol as sole carbon source at room temperature $\left(20-23{ }^{\circ} \mathrm{C}\right)$, both in liquid medium and on solid medium plates. In liquid VM media without shaking, the strain initially formed small aggregates or white flocks. On agar plates, milky white to cream-coloured colonies were formed within 3-4 days, which turned light yellow at the periphery after extended incubations. Cells were slightly curved, non-motile rods and tended to form aggregates (Fig. 1). Gas vesicles were formed occasionally inside the cells in ageing cultures.

Strain Dia- $1^{\mathrm{T}}$ grew well in VM-ethanol medium and did not grow in nutrient broth only, i.e. a sugar or ethanol was required for growth. Growth tests with the API 20NE system and the Biolog microplate system (PM1 microplate) showed that the strain grew in the presence of a wide variety of sugars, and some organic acids and alcohols (see species description). Strain Dia- $1^{\mathrm{T}}$ grew optimally at $20-25^{\circ} \mathrm{C}$, with a doubling time of approximately $40 \mathrm{~h}$. Temperatures up to $30{ }^{\circ} \mathrm{C}$ were tolerated, but no growth was observed at $37^{\circ} \mathrm{C}$ or at $15{ }^{\circ} \mathrm{C}$. The optimum $\mathrm{pH}$ for growth was $\mathrm{pH} 6.5-7.0$; with the limits of growth at pH 5.5 and 8.0.

Nil or very weak growth was found in mineral medium free of bound nitrogen compounds. The acetylene reduction test was negative even after prolonged incubation for 


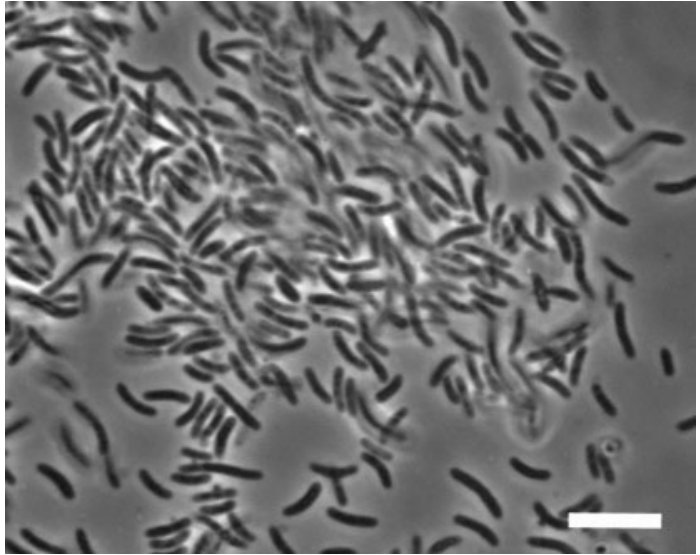

Fig. 1. Phase-contrast micrograph of aggregated cells of strain Dia-1 ${ }^{\top}$ grown in 1:10-diluted nutrient broth medium containing $10 \mathrm{mM}$ glucose. Bar, $5 \mu \mathrm{m}$.

2 days. The nifH gene could not be amplified using a direct or a nested PCR approach (Zani et al., 2000).

According to the FAME profile, strain Dia- $1^{\mathrm{T}}$ showed similarity to representatives of the Roseomonas group cervicalis which is synonymous with Azospirillum brasilense. The major fatty acids were $18: 1 \omega 7 c(55 \%), 18: 12-\mathrm{OH}(12 \%)$ and $16: 0(10 \%)$.

Ubiquinone Q-10 was found to be the only respiratory quinone. Analysis of polar lipids identified phosphatidylglycerol, phosphatidylethanolamine, phosphatidylmonomethylethanolamine and two aminolipids as dominant lipid constituents. The following polyamines were found $\left(\mu \mathrm{mol} \mathrm{g}{ }^{-1}\right)$ : putrescine, 60.4 ; cadaverine, 0.5 ; spermidine, 1.8; sym-homospermidine, 13.5; and spermine, 1.0.

According to the $16 \mathrm{~S}$ rRNA gene sequence analysis, strain Dia- $1^{\mathrm{T}}$ was closest related to representatives of the genera Azospirillum (90-91\% gene sequence similarity), Skermanella (88-89\%), Rhodocista (87-88\%) and Dongia (88$89 \%$ ) (Fig. 2). The robustness of the tree was confirmed by minimum evolution, neighbour-joining and maximumlikelihood methods (1000 replications each) in MEGA5 software, and the 16S rRNA gene sequence of strain Dia- $1^{\mathrm{T}}$ was added to the 'All-Species Living Tree' LTPs104 (March 2011) (Yarza et al., 2008). All methods yielded trees of similar topology and the position of strain Dia- $1^{\mathrm{T}}$ was similar in all trees.

The DNA G $+C$ content of strain Dia- $1^{\mathrm{T}}$ was $61.0 \pm$ $1.5 \mathrm{~mol} \%$.

Based on the 16S rRNA gene sequence analysis (Fig. 2) and the various phenotypic properties analysed (Table 1), strain Dia- $1^{T}$ is proposed to represent a novel species in a new genus. It differs from members of the genus Dongia by the presence of catalase and oxidase, and the lack of nitrate reduction; from members of the genus Azospirillum by the lack of the characteristic ability to fix nitrogen; from Azospirillum and Skermanella by the lack of nitrate reduction; and from Rhodocista by a different metabolism. It differs from all these genera by a substantially lower DNA $\mathrm{G}+\mathrm{C}$ content, and by a different pattern of substrate utilization (Table 1). We therefore conclude that strain Dia- ${ }^{\mathrm{T}}$ represents a novel species of a new genus for which

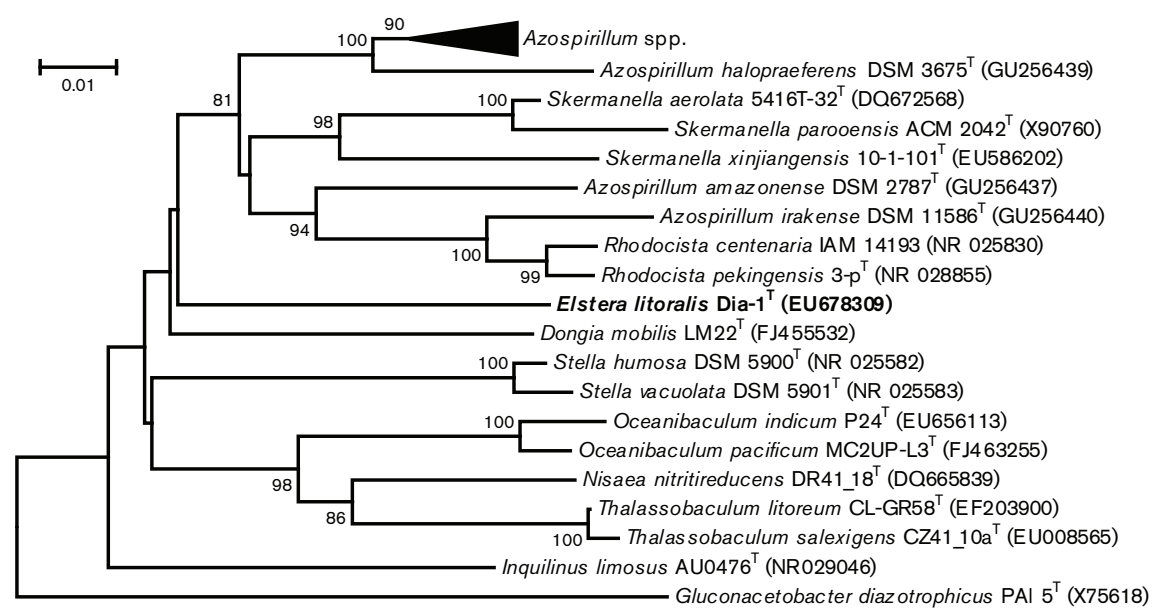

Fig. 2. Phylogenetic tree of strain $\mathrm{Dia}-1^{\top}$ and related members of the family Rhodospirillaceae based on $16 \mathrm{~S}$ rRNA gene sequences. The tree was constructed using the Minimum Evolution method. Bootstrap values of 1000 replications are shown next to the branches. Evolutionary distances were computed using the Tamura-Nei method with a total of 1207 positions used for analysis. Species present in the collapsed branch: A. lipoferum NCIMB $11861^{\top}$ (Genbank accession no. Z29619), $A$. melinis TMCY 0552 ${ }^{\top}$ (DQ022958), A. oryzae COC8 ${ }^{\top}$ (AB185396), A. zeae N7 ${ }^{\top}$ (DQ682470), A. doebereinerae GSF71 ${ }^{\top}$ (NR025354), A. thiophilum BV-S ${ }^{\top}$ (EU678791), A. picis IMMIB TAR-3 ${ }^{\top}$ (AM922283), $A$. canadense DS2 ${ }^{\top}$ (DQ393891), A. rugosum IMMIB AFH-6 ${ }^{\top}$ (AM419042), A. brasilense DSM 1690 ${ }^{\top}$ (GU256438). Bar, $1 \%$ sequence divergence. 
Table 1. Comparison of strain $\mathrm{Dia}-1^{\top}$ with related genera from Fig. 2

Taxa: 1, Dia-1 ${ }^{\mathrm{T}}$; 2, Dongia; 3, Azospirillum; 4, Skermanella; 5, Rhodocista. Data for reference genera from Liu et al. (2010), Mehnaz et al. (2007), Sly \& Stackebrandt (1999) and Kawasaki et al. (1992). +, Positive; w, weakly positive; -, negative; v, variable; ND, no data available.

\begin{tabular}{|c|c|c|c|c|c|}
\hline Characteristic & 1 & 2 & 3 & 4 & 5 \\
\hline Metabolic type & Chemotrophic & Chemotrophic & Chemotrophic & Chemotrophic & Phototrophic \\
\hline Oxidase & + & - & + & + & ND \\
\hline Major quinones & Q-10 & Q-10 & Q-10 & Q-10, Q-8 & Q-9 \\
\hline $\mathrm{N}_{2}$ fixation & - & $\mathrm{ND}$ & + & - & $\mathrm{ND}$ \\
\hline Nitrate reduction to nitrite & - & + & + & + & - \\
\hline L-Arabinose & + & $\mathrm{W}$ & $\mathrm{v}$ & + & ND \\
\hline D-Glucose & + & $\mathrm{W}$ & $\mathrm{v}$ & + & - \\
\hline L-Rhamnose & + & - & $\mathrm{v}$ & + & ND \\
\hline Sucrose & - & $\mathrm{W}$ & $\mathrm{v}$ & ND & - \\
\hline Citrate & - & - & $\mathrm{V}$ & + & - \\
\hline myo-Inositol & + & - & $\mathrm{V}$ & - & ND \\
\hline
\end{tabular}

the name Elstera litoralis gen. nov., sp. nov. is proposed. The type strain of the type species is strain Dia- $1^{\mathrm{T}}$.

\section{Description of Elstera gen. nov.}

Elstera (Els'te.ra. N.L. fem. n. Elstera named after HansJoachim Elster, a German limnologist working on Lake Constance who was one of the first to establish the importance of the littoral zone for the lake ecosystem).

Cells are Gram-negative rods, catalase- and oxidasepositive. Chemoheterotrophic. Sugars, some organic acids and alcohols are preferred substrates. Ubiquinone Q-10 is the dominant quinone and putrescine is the dominant polyamine. The type species is Elstera litoralis.

\section{Description of Elstera litoralis sp. nov.}

Elstera litoralis (li.to' ra.lis. L. fem. adj. litoralis belonging to the shore or the littoral).

Exhibits the following properties in addition to those listed in the genus description. Cells are slightly curved rods, $1.0 \times 2.0-5.0 \mu \mathrm{m}$ in size, non-motile, with a minimum doubling time of approximately $40 \mathrm{~h}$. Milky white to cream colonies form on diluted nutrient broth agar supplemented with glucose after 3-4 days. Growth occurs at $10-25{ }^{\circ} \mathrm{C}$ (optimum, 20-25 ${ }^{\circ} \mathrm{C}$ ) and at $\mathrm{pH}$ 5.5-8.0 (optimum, $\mathrm{pH}$ 6.5-7.0). Negative result in tests for reduction of nitrate, sulfate, and iron(III), fixation of molecular nitrogen, and indole production from tryptophan. Grows in the presence of D-glucose, D-mannose, L-rhamnose, D-fructose, L-fructose, D-galactose, L-fucose, L-arabinose, D-xylose, L-lyxose, D-ribose, D-mannitol, D-sorbitol, $\alpha$-methyl-D-galactoside, $N$-acetyl-D-glucosamine, methyl $\beta$-D-glucoside, D-glucuronic acid, D-galactonic acid, D-glucose 6-phosphate, myoinositol, glycerol, ethanol, L-malate, L-glutamate, L-alanine, L-serine, L-proline, glycyl L-proline; but weak or no growth observed in presence of trehalose, D-maltose, melibiose, $\alpha$-Dlactose, lactulose, sucrose, D-psicose, cellobiose, maltotriose, dulcitol, adonitol, D-saccharic acid, D-galactonic acid- $\gamma$ lactone, D-fructose 6-phosphate, inosine, $\mathrm{N}$-acetyl- $\beta$ - $O$ mannosamine, glucuronamide, D-glucosaminic acid, Lgalactonic acid- $\gamma$-lactone, formate, acetate, propionate, pyruvate, methylpyruvate, L-lactate, D-malate, fumarate, succinate, monomethylsuccinate, bromosuccinate, glycolate, glyoxylate, citric acid, $m$-tartrate, 2-oxoglutarate, acetoacetate, 2-hydroxybutyrate, 2-hydroxyglutaric acid- $\gamma$-lactone, 2-ketobutyrate, tricarballylic acid, $\alpha$-glycerophosphate, mucic acid, L-threonine, D-threonine, L-aspartate, L-asparagine, L-glutamine, D-alanine, D-serine, D-aspartate, tyramine, L-alanylglycine, glycyl L-glutamate, glycyl L-aspartate, thymidine, 2-deoxyadenosine, $p$-hydroxyphenylacetate, phenylethylamine, 1,2-propanediol, 2-aminoethanol, Tweens 20, 40 and 80 . Major cellular fatty acids are $18: 1 \omega 7 c, 18: 12-\mathrm{OH}$ and $16: 0$.

The type strain Dia- ${ }^{\mathrm{T}}$ (=DSM $19532^{\mathrm{T}}=\mathrm{LMG} 24234^{\mathrm{T}}$ ), was isolated from biofilms on stones in the littoral zone of Lake Constance, Germany. The DNA G $+\mathrm{C}$ content of strain Dia-1 is $61.0 \pm 1.5 \mathrm{~mol} \%$.

\section{Acknowledgements}

The authors want to thank Hans-Jürgen Busse, Vienna, Austria, for analysis of polyamines. We also thank Antje Wiese for technical help in characterization of the strain. This study was supported by the Deutsche Forschungsgemeinschaft, Bonn, with Sonderforschungsbereich (SFB) 454, and research funds of Universität Konstanz.

\section{References}

Bahulikar, R. A. \& Kroth, P. G. (2008). The complex extracellular polysaccharides of mainly chain-forming freshwater diatom species from epilithic biofilms. J Phycol 44, 1465-1475. 
Bruckner, C. G., Bahulikar, R., Rahalkar, M., Schink, B. \& Kroth, P. G. (2008). Bacteria associated with benthic diatoms from Lake Constance: phylogeny and influences on diatom growth and secretion of extracellular polymeric substances. Appl Environ Microbiol 74, 7740-7749.

Busse, H.-J. \& Auling, G. (1988). Polyamine pattern as a chemotaxonomic marker within the Proteobacteria. Syst Appl Microbiol 11, 1-8.

DuBois, M., Gilles, K. A., Hamilton, J. K., Rebers, P. A. \& Smith, F. (1956). Colorimetric method for determination of sugars and related substances. Anal Chem 28, 350-356.

Kawasaki, H., Hoshino, Y., Kuraishi, Y. \& Yamasato, K. (1992). Rhodocista centenaria gen. nov., sp. nov., a cyst-forming anoxygenic photosynthetic bacterium and its phylogenetic position in the Proteobacteria alpha group. J Gen Appl Microbiol 38, 541-551.

Liu, Y., Jin, J. H., Liu, Y. H., Zhou, Y. G. \& Liu, Z. P. (2010). Dongia mobilis gen. nov., sp. nov., a new member of the family Rhodospirillaceae isolated from a sequencing batch reactor for treatment of malachite green effluent. Int J Syst Evol Microbiol 60, 2780-2785.

Mehnaz, S., Weselowski, B. \& Lazarovits, G. (2007). Azospirillum canadense sp. nov., a nitrogen-fixing bacterium isolated from corn rhizosphere. Int J Syst Evol Microbiol 57, 620-624.

Mesbah, M., Premachandran, U. \& Whitman, W. B. (1989). Precise measurement of the $\mathrm{G}+\mathrm{C}$ content of deoxyribonucleic acid by highperformance liquid chromatography. Int J Syst Bacteriol 39, 159-167.

Murray, M. G. \& Thompson, W. F. (1980). Rapid isolation of high molecular weight plant DNA. Nucleic Acids Res 8, 4321-4326.

Rahalkar, M., Bussmann, I. \& Schink, B. (2007). Methylosoma difficile gen. nov., sp. nov., a novel methanotroph enriched by gradient cultivation from littoral sediment of Lake Constance. Int J Syst Evol Microbiol 57, 1073-1080.

Rao, T. S., Rani, P. G., Venugopalan, V. P. \& Nair, K. V. K. (1997). Biofilm formation in a freshwater environment under photic and aphotic condition. Biofouling 11, 265-282.

Reinhold-Hurek, B. \& Hurek, T. (2000). Reassessment of the taxonomic structure of the diazotrophic genus Azoarcus sensu lato and description of three new genera and new species, Azovibrio restrictus gen. nov., sp. nov., Azospira oryzae gen. nov., sp. nov. and Azonexus fungiphilus gen. nov., sp. nov. Int J Syst Evol Microbiol 50, 649-659.

Schmieder, K., Piepho, H.-P. \& Schröder, H. G. (2005). Spatial models as a tool to identify spatial patterns of surficial sediment composition and their contributing factors in the littoral zone of Lake Constance (Germany). Aquat Sci 67, 326-336.

Sly, L. I. \& Stackebrandt, E. (1999). Description of Skermanella parooensis gen. nov., sp. nov. to accommodate Conglomeromonas largomobilis subsp. parooensis following the transfer of Conglomeromonas largomobilis subsp. largomobilis to the genus Azospirillum. Int J Syst Bacteriol 49, 541-544.

Stevenson, R. J., Bothwell, M. I. \& Lowe, R. L. (1996). Algal Ecology: Freshwater Benthic Ecosystem. California: Academic Press.

Stewart, W. D. P., Fitzgerald, G. P. \& Burris, R. H. (1967). In situ studies on nitrogen fixation with the acetylene reduction technique. Science 158, 536.

Stolz, A., Busse, H.-J. \& Kämpfer, P. (2007). Pseudomonas knackmussii sp. nov. Int J Syst Evol Microbiol 57, 572-576.

Tamura, K., Peterson, D., Peterson, N., Stecher, G., Nei, M. \& Kumar, S. (2011). MEGA5: molecular evolutionary genetics analysis using maximum likelihood, evolutionary distance, and maximum parsimony methods. Mol Biol Evol 28, 2731-2739.

Watanabe, M. M. (2005). Freshwater culture media. In Algal Culturing Techniques, pp. 13-20. Edited by R. A. Anderson. Burlington, MA: Elsevier Academic Press.

Yarza, P., Richter, M., Peplies, J., Euzeby, J., Amann, R., Schleifer, K. H., Ludwig, W., Glöckner, F. O. \& Rosselló-Móra, R. (2008). The all-species living tree project: a $16 \mathrm{~S}$ rRNA-based phylogenetic tree of all sequenced type strains. Syst Appl Microbiol 31, 241-250.

Zani, S., Mellon, M. T., Collier, J. L. \& Zehr, J. P. (2000). Expression of nifH genes in natural microbial assemblages in Lake George, New York, detected by reverse transcriptase PCR. Appl Environ Microbiol 66, 3119-3124. 